\title{
REVIEW
}

\section{Airway Mucociliary Function at High Altitude}

\author{
George W. Rodway, PhD, CRNP; Jeremy S. Windsor, MB, ChB \\ From The Ohio State University College of Nursing, Columbus, $\mathrm{OH}$ (Dr Rodway); and the Centre for Aviation, Space and Extreme \\ Environment Medicine (CASE), University College, London, UK (Dr Windsor and Dr Rodway).
}

\begin{abstract}
Despite the presence of a number of anecdotal reports in the mountaineering literature, mucociliary dysfunction at high altitude has received little scientific attention. However, the dry, cold, thin air at high altitude has the potential to undermine normal mucociliary function. This seems increasingly likely in mountaineers who also experience dehydration, nasal obstruction, and extremes of aerobic respiration when climbing in such environments. These factors may result in a number of clinical conditions that range from sore throats and coughs commonly seen at altitude to rarer cases of bronchiolar collapse and lung atelectasis. The purpose of this review is to discuss the etiology of mucociliary dysfunction at altitude and outline a number of potential solutions to the problems this phenomenon presents.
\end{abstract}

Key words: high altitude, mucociliary function, hypoxia, cholinergic antagonist, mountaineering

\section{Introduction}

The extraordinary environmental conditions at high altitudes have the potential to directly damage the respiratory tract. This can present in a number of different ways, ranging from sore throats and coughs commonly seen at altitude to rarer cases of bronchiolar collapse and lung atelectasis. At a time when optimum gas exchange is essential, any damage to the respiratory tract is potentially life threatening. One of the earliest illustrations of this was made by Howard Somervell after his attempt on Mt Everest in 1924:

Finally, as we approached the level of 28,000 feet [8534 $m]$, the summit being only half a mile away or less, I felt that, as far as I was concerned, it was hopeless to continue. I told Norton that he had no chance of the summit with me. My throat was not only extremely painful, but was getting almost blocked up-why, I knew not. ... Somewhere about 25,000 feet [7620 m] high [on the descent], when darkness was gathering, I had one of my fits of coughing and dislodged something in my throat which stuck so that I could breathe neither in nor out. I could not, of course, make a sign to Norton, or stop him, for the rope was off now; so I sat in the snow to die whilst he walked on, little knowing that his companion was awaiting the end only a few yards behind him. I made

Corresponding author: George W. Rodway, PhD, CRNP, College of Nursing, The Ohio State University, 1585 Neil Ave, Columbus, OH 43210 (e-mail: gwrodway@ hotmail.com). one or two attempts to breathe, but nothing happened. Finally, I pressed my chest with both hands, gave one last almighty push-and the obstruction came up. What a relief! Coughing up a little blood, I once more breathed really freely-more freely than I had done for some days. ${ }^{1}$

Despite advances in technology and techniques, similar events continue to occur. After his successful ascent of Mt Everest via the Kangshung face, Stephen Venables $^{2}$ wrote on his return to high camp at $7450 \mathrm{~m}$ : "Thirst and a croaking cough woke me at dawn on May $15^{\text {th }}$ [1988]. For ages I lay inert, coughing up foul lumps of phlegm from my throat." In 1997, a scientific report of damage to the respiratory tract at altitude was presented to the International Congress of Mountain Medicine held in Interlaken, Switzerland. ${ }^{3}$ This case highlighted the experience of a 54-year-old man who collapsed at $7300 \mathrm{~m}$ and was subsequently diagnosed with "[a]cute necrotic laryngitis, obstruction of upper respiratory canals (foreign body type), and the development of an acute cardiovascular and respiratory insufficiency." After a descent to a camp at approximately 6000 $\mathrm{m}$, the victim was treated by "cleaning of the upper respiratory canals performed under direct laryngoscopy." Fortunately, this allowed him to descend unaided to base camp, where he was able to make a full recovery.

Damage to the respiratory tract can also predispose mountaineers to sore throats and coughs. Although these are rarely life threatening, they are commonplace at high 


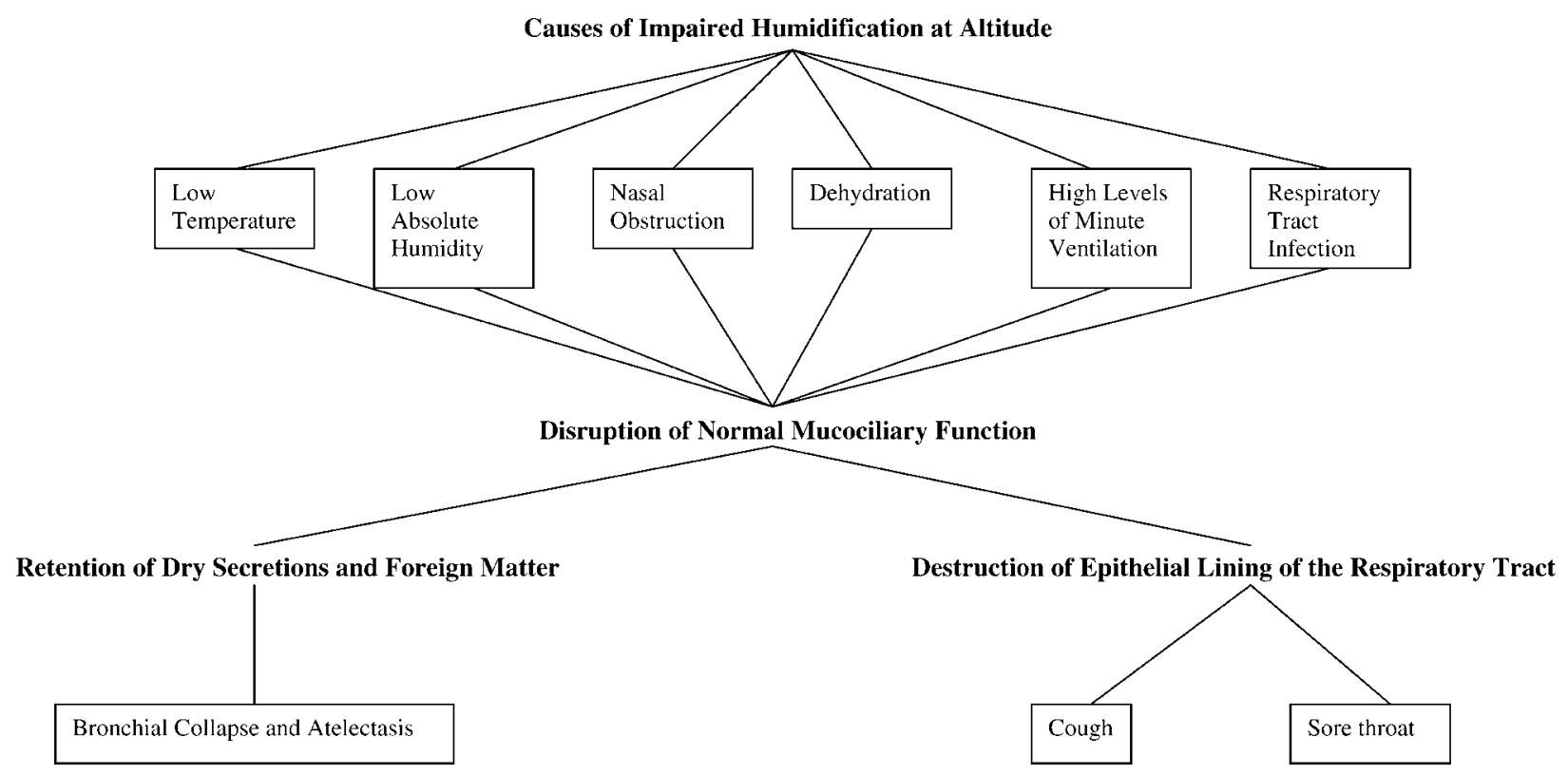

Figure. The causes and consequences of impaired humidification of inspired gases at altitude.

altitude and a source of considerable misery. Indeed, Eric Shipton described them as "potent factors in our failure to reach the summit" after his attempt on Mt Everest in $1933 .{ }^{4}$

Despite these examples, damage to the respiratory tract at high altitude has received little scientific attention in the medical literature. Nevertheless, it is possible to begin to address this omission here by bringing together the available evidence from high-altitude studies and combining it with research from a range of other medical fields. This review will attempt to identify those factors responsible for mucociliary dysfunction at high altitude and outline the ways in which this phenomenon can be addressed.

\section{Physiology}

In normal conditions, inspired gases are warmed to body temperature and saturated with water vapor at a point just below the carina. ${ }^{5}$ This region is commonly referred to as the isothermic saturation point (ISP) and ensures that the mucociliary transport system is able to remove surface liquids and particles quickly and efficiently. ${ }^{6}$ Normally, mucus moves at a speed of $10 \mathrm{~mm} \cdot \mathrm{min}^{-1}$ and takes approximately 20 minutes to reach the hypopharynx. ${ }^{7}$ However, if the ISP is shifted distally by either environmental or physiological factors, the passage of mucus slows and eventually ceases. ${ }^{8}$ The mucociliary transport system needs 2 fully functioning layers to be effective. First is a layer of ciliated epithelia bathed in a watery liquid (sol), followed by an overlying layer of viscous gel (mucus) 5 to $6 \mu \mathrm{m}$ thick that is responsible for transporting particles along the tips of the cilia. With a shift in the location of the ISP, bronchi that normally function in ideal conditions are forced to take part in heat and moisture exchange. ${ }^{6}$ Unfortunately, these cells dehydrate quickly, causing neighboring mucus and sol layers to dry and ciliary function to cease. ${ }^{9}$ This has been demonstrated by Barry et al, ${ }^{10}$ who measured the nasal mucociliary transport of trekkers visiting Mt Everest Base Camp (5300 m). By placing saccharin in the anterior part of the nose and measuring the time taken to elicit a sweet taste in the mouth, the researchers demonstrated a marked increase in saccharin time from a mean of 11 minutes at sea level to 60 minutes at $\mathrm{Mt}$ Everest Base Camp. In practice, a result of 60 minutes is a dramatic finding at altitude, as it implies that absolutely no saccharin was tasted during the time span of the test and that it is therefore conceivable that a response would take considerably longer. Interestingly, even after 2 weeks of acclimatization at altitudes of 5000 $\mathrm{m}$ and above, the median saccharin time remained 60 minutes (95\% CI, 38-60 minutes), suggesting that mucociliary function is unable to recover at this elevation.

The retention of viscous mucus caused by mucociliary dysfunction can also lead to widespread cellular damage. Dehydration of the respiratory tract causes epithelial damage in the trachea and bronchi, which can lead to "reduced tissue elasticity with ultimate collapse of bronchioles, mucosal swelling and atelectasis." 5 We hypothesize that a combination of factors commonly seen at high altitude (Figure) causes a distal shift in ISP that 
contributes to the respiratory difficulties previously described. These are outlined below.

\section{TEMPERATURE}

For many years, anesthesiologists have recognized that the inspiration of cold, dry gases can impair the warming and humidification process necessary to maintain a normal ISP. ${ }^{11}$ At high altitude, ambient temperature falls by approximately $1^{\circ} \mathrm{C}$ for every $150 \mathrm{~m}$ of ascent, resulting in temperatures on the summit of Mt Everest $(8850 \mathrm{~m})$ between $-20^{\circ} \mathrm{C}$ and $-60^{\circ} \mathrm{C} .{ }^{12}$ This can affect the ISP in 2 ways: low temperature and reduced humidification.

\section{Low temperature}

A number of animal and in vitro studies have consistently demonstrated that mucociliary clearance rates fall after exposure to low temperatures. ${ }^{5-7}$ Although studies on human volunteers have been limited by ethical concerns and problems with measurement, work by Proctor et $\mathrm{al}^{13}$ has demonstrated a small but significant decrease in the rate of nasal mucociliary flow in resting human volunteers breathing air cooled to $15^{\circ} \mathrm{C}$. Although no evidence is available at lower temperatures, it is reasonable to assume this change would be magnified on the summit of an 8000-m mountain where temperatures are considerably colder and levels of minute ventilation can far exceed normal resting levels.

\section{Reduced humidification}

A fall in temperature can also reduce the amount of saturated water vapor present in ambient air. Normally, the absolute humidity (AH) at the ISP is $43 \mathrm{~g} \cdot \mathrm{m}^{-3}$; however, after the inspiration of dry gas this can fall sharply. Although the exact amount of humidification needed to maintain normal mucociliary function remains uncertain, Forbes ${ }^{14}$ found that at $37^{\circ} \mathrm{C}$ an $\mathrm{AH}$ equivalent to 32 $\mathrm{g} \cdot \mathrm{m}^{-3}$ caused mucus flow to fall significantly in healthy human volunteers, whereas at an $\mathrm{AH}$ of $22 \mathrm{~g} \cdot \mathrm{m}^{-3} \mathrm{mu}-$ cociliary function ceased completely. The Table demonstrates that in order to maintain an $\mathrm{AH}$ of $32 \mathrm{~g} \cdot \mathrm{m}^{-3}$ or more, inspired gases must be heated to approximately $32^{\circ} \mathrm{C}$ to hold enough saturated water vapor in the air. This represents a considerable challenge to anyone exercising in a cold, high-altitude region.

\section{NASAL OBSTRUCTION}

The convoluted surfaces of the nasal mucosa provide a large, highly vascular surface area that is well suited to the warming and humidification of inspired gases. This
Table. The influence of temperature on saturated vapor pressure and absolute humidity*

\begin{tabular}{ccc}
\hline $\begin{array}{c}\text { Temperature, } \\
{ }^{\circ} \mathrm{C}\end{array}$ & $\begin{array}{c}\text { Saturated vapor } \\
\text { pressure, } \mathrm{mm} \mathrm{Hg}\end{array}$ & $\begin{array}{c}\text { Absolute } \\
\text { humidity, } g \cdot \mathrm{m}^{-3}\end{array}$ \\
\hline 0 & 4.6 & 4.8 \\
10 & 9.2 & 9.3 \\
20 & 17.5 & 17.1 \\
30 & 31.3 & 30.4 \\
37 & 47.1 & 43.4 \\
\hline
\end{tabular}

*As ambient temperature increases, the saturated vapor pressure of water rises together with highest possible absolute humidity. To achieve an absolute humidity of $>30 \mathrm{~g} \cdot \mathrm{m}^{-3}$, the temperature within the trachea must be $30^{\circ} \mathrm{C}$.

was demonstrated in a small experiment conducted by Ingelstedt, ${ }^{15}$ who measured the temperature and relative humidity (the $\mathrm{AH}$ in the environment divided by the maximum humidity for the given temperature and pressure expressed as a percentage) through a cricothyroid puncture in healthy human volunteers breathing air at room temperature. During inspiration through the nose, a mean temperature of $32^{\circ} \mathrm{C}$ and a relative humidity of $98 \%$ were recorded at the needle site, compared with a temperature of $30.5^{\circ} \mathrm{C}$ and relative humidity of $90 \%$ when breathing through the mouth. Unfortunately, nasal obstruction is common at high altitudes. This was first described by Barry et $\mathrm{al}^{10}$ in a study of 54 lowlanders who participated in a trek to Mt Everest Base Camp (5300 m). On departure from the United Kingdom, the median nasal obstruction score at sea level was 0 (range $0-2$ ), and on arrival at $5300 \mathrm{~m}$ the score increased to 1 . Twenty-three subjects $(43 \%)$ described symptoms of subjective nasal blockage, and only 7 (13\%) noticed any improvements in nose breathing $(P<.01) .{ }^{10}$ This would suggest that at the point when optimum warming and humidification is necessary, the nasal cavity's contribution may be limited.

\section{HYPOXIA}

In vitro tests conducted on the tracheas of animals have demonstrated impairment of mucociliary clearance under hypoxic conditions. ${ }^{16,17}$ Although these changes have not been demonstrated in humans, work conducted by members of the Operation Everest III team offer a fascinating insight into the effects of hypoxia on the upper respiratory tract. By using a hypobaric chamber, the group was able to examine the effects of hypobaric hypoxia on oral and nasal peak inspiratory flow while temperature $\left(18^{\circ} \mathrm{C}-24^{\circ} \mathrm{C}\right)$ and humidity (relative humidity $30 \%-60 \%$ ) were controlled. ${ }^{18}$ Because of a reduction in 
gas density, the expected increase in inspiratory flow was found. However, the increase in oral flow (47\% \pm $14 \%$ ) was significantly higher than nasal inspiratory flow $(16 \% \pm 12 \%)$ at altitudes above $5000 \mathrm{~m}$. This difference may be explained by a number of hypotheses, including 1) an increase in nasal erectile tissue size as a result of attempts to warm and humidify the larger volumes of inspired air; 2) the effects of peripheral edema (commonly seen in acute mountain sickness) in a rigid bony structure; and 3) the results of rhinitis, which is often seen at altitude. ${ }^{19,20}$ These results demonstrate for the first time that hypobaric hypoxia affects the movement of air through the nasal passages. This may, in turn, have implications for a mucociliary system that is already under considerable stress.

\section{DEHYDRATION}

To humidify large volumes of cold, dry gas, maintaining an optimal hydration status seems prudent. Historically, respiratory water loss during heavy exercise in highmountain environments was thought to be considerable. Indeed, Griffith Pugh, the physiologist associated with the first successful expedition to Mt Everest in 1953, estimated daily respiratory water losses of between 1 and $2 \mathrm{~L}$ during exercise at extreme altitude. ${ }^{21}$ However, as a result of expired gases often remaining below body temperature and only partially saturated with water, it is likely that this value is an overestimation and that respiratory water loss is likely to be considerably less. ${ }^{22}$ Nevertheless, the ability of mountaineers to humidify inspired gases will be affected to some extent during episodes of dehydration.

\section{RESPIRATORY TRACT INFECTION}

At high altitude, respiratory tract infections are common. In a study conducted on Cerro Aconcagua (6895 m), 13 of a group of 19 mountaineers displayed signs and symptoms of bronchitis at $4300 \mathrm{~m} .{ }^{23}$ In addition, there are numerous anecdotal reports of sinusitis, laryngitis, and pharyngitis among those who spend time at high altitude. ${ }^{24}$ Although the impact of these infections on the mucociliary system has not been studied at high altitude, it is reasonable to expect some degree of disruption to normal function.

\section{Treatment}

The Swiss mountaineer Edouard Wyss Dunant once described the highest slopes of Mt Everest as the todeszone ("death zone"), a place where acclimatization is impossible and deterioration is rapid. Extreme-altitude moun- taineers of today acknowledge this and prefer to acclimatize at lower altitudes before venturing above 7000 $\mathrm{m}$. Inadvertently, this benefits the mucociliary system by 1) minimizing exposure to the cold, dry, hypoxic air found at extreme altitude; 2) maintaining adequate levels of hydration and energy intake for as long as possible; and 3 ) ensuring an adequate period of recovery from infection. The widespread use of supplemental oxygen on the world's 8000-m peaks also has important benefits for the mucociliary system. Supplemental oxygen can reduce minute ventilation and hence lengthen the period of time that inspired gases can be heated and humidified. This process is enhanced by the oxygen mask itself-it has the potential to trap in-flowing gases, warming and humidifying them before they enter the respiratory tract.

Individuals who are most troubled by the consequences of mucociliary dysfunction at high altitude may also find some benefit in relieving nasal congestion. Although the majority of breathing during climbing will be through the mouth, long periods of time are spent at rest when nose breathing often predominates. Nasal obstruction can be relieved by the use of anticholinergics, which block the parasympathetic innervation to the submucous glands inside the nose. Although clinical research addressing this phenomena is limited, a number of investigators have examined the effect of local applications of ipratropium bromide 25,26 and atropine sulfate ${ }^{19}$ on persons with rhinorrhoea and other nasal symptoms triggered by cold conditions. Although both agents have been shown to reduce rhinorrhoea and relieve nasal congestion, atropine sulfate has been shown to reduce ciliary function and therefore interfere with mucociliary clearance. ${ }^{26}$ However, ipratropium bromide used in divided doses of between 160 and $360 \mathrm{mg}$ has been shown to be effective in reducing nasal symptoms without compromising ciliary function. ${ }^{25,26}$

\section{Summary}

Disruption to the normal mucociliary function of the respiratory tract is a potential problem facing all sojourners to high-altitude regions. Although the human body can adapt to high altitude in a number of different ways, there is no evidence to suggest that mucociliary function improves with prolonged exposure to this environment. At present, there is little evidence to support the use of any intervention that can prevent the conditions outlined in this review. Nevertheless, it appears sensible to minimize nasal obstruction, dehydration, and time spent at extreme altitude. Additionally, by acclimatizing appropriately and ensuring that a sufficient supply of supplemental oxygen is available for persons climbing at great 
altitudes, it may be possible to reduce the harmful effects of this harsh setting on the mucociliary system.

\section{Acknowledgment}

The authors wish to thank Dr James Milledge for providing invaluable assistance in the preparation of this manuscript.

\section{References}

1. Somervell TH. After Everest: The Experiences of a Mountaineer and Medical Missionary. London, UK: Hodder Stoughton Ltd; 1936.

2. Venables S. Everest: Alone at the Summit. New York, NY: Thunder's Mouth Press; 2000:195.

3. Salova K. Acute respiratory insufficiency in high-altitude alpinism caused by mechanical obstruction. International Congress of Mountain Medicine. Interlaken, Switzerland; 1997:25.

4. Steele P. Eric Shipton-Everest and Beyond. London, UK: Constable; 1998:46.

5. Shelly MP, Lloyd GM, Park GR. A review of the mechanisms and methods of humidification of inspired gases. Intensive Care Med. 1988;14:1-9.

6. Hedley RM, Allt-Graham J. Heat and moisture exchangers and breathing filters. Br J Anaesth. 1994;73:227-236.

7. Shapiro BA, Peruzzi WT. Respiratory care. In: Miller RD, ed. Anaesthesia. 5th ed. New York, NY: Churchill Livingstone; 2000:2405-2407.

8. Dery R. The evolution of heat and moisture in the respiratory tract during anaesthesia with a non-rebreathing system. Can Anaesth Soc J. 1973;20:296-309.

9. Chalon J, Patel C, Ali M, et al. Humidity and the anaesthetized patient. Anaethesiology. 1979;50:195-198.

10. Barry PW, Mason NP, O'Callaghan C. Nasal mucociliary transport is impaired at altitude. Eur Respir J. 1997;10: 35-37.

11. Chalon J, Dolores AY, Loew D, Malebranche J. Effects of dry anaesthetic gases on tracheobronchial ciliated epithelium. Anaesthesiology. 1972;37:338-343.

12. Ward MP, Milledge JS, West JB. High Altitude Medicine and Physiology. London, UK: Arnold; 2000.

13. Proctor DF, Anderson I, Lundqvist GR. Human nasal mucosal function at controlled temperatures. Respir Physiol. 1977;30:109-124.

14. Forbes AR. Humidification and mucus flow in the intubated trachea. Br J Anaesth. 1973;45:29-34.

15. Ingelstedt S. Studies on the conditioning of air in the respiratory tract. Acta Otolarygol Suppl. 1956;131:1-80.

16. Dalhamn T, Rosengren A. The effect of oxygen lack on the tracheal ciliary activity. Arch Environ Health. 1968; 16:371-373.

17. Laurenzi GA, Yen S, Guarneri JM. Adverse effect of oxygen on tracheal mucus flow. $N$ Engl J Med. 1968;279: 333-339.

18. Barry PW, Mason NP, Richalet JP. Nasal peak inspiratory flow at altitude. Eur Respir J. 2002;19:16-19.

19. Silvers WS. The skier's nose: a model of cold-induced rhinorrhea. Ann Allergy. 1991;67:32-36.

20. Bonadonna P, Senna G, Zanon P, et al. Cold-induced rhinitis in skiers-clinical aspects and treatment with ipratropium bromide nasal spray: a randomized controlled trial. Am J Rhinol. 2001;15:297-301.

21. Pugh LGCE, Ward MP. Some effects of high altitude on man. Lancet. 1956; Dec 1:1115-1121.

22. Milledge JS. Respiratory water loss at altitude. The Newsletter of the International Society of Mountain Medicine. 1992;2:5-7.

23. Rabold MB. High Altitude Bronchitis on Cerro Aconcagua (Aspen, Colorado, 1987). Program and Abstracts of the Wilderness Medical Society (WMS). Colorado Springs, CO: Wilderness Medical Society; 1987.

24. Basnyat B, Cumbo TA, Edelman R. Infections at high altitude. Clin Infect Dis. 2001;33:1887-1891.

25. Ostberg B, Winther B, Mygind N. Cold air-induced rhinorrhea and high-dose ipratropium. Arch Otolaryngol Head Neck Surg. 1987;113:160-162.

26. Wanner A. Effect of ipratropium bromide on airway mucociliary function. Am J Med. 1986;81:23-27. 